\title{
New Liquid Crystalline Tolanes from (-)-Menthone
}

\author{
Fernando Ely, Adailton J. Bortoluzzi, Hugo Gallardo, \\ Department of Chemistry \\ Universidade Federal de Santa Catarina, CEP 88040-900, Florianópolis, SC, Brazil \\ and Aloir A. Merlo \\ Institute of Chemistry \\ Universidade Federal do Rio Grande do Sul, CEP 91510-970, Porto Alegre, RS, Brazil
}

Received on 16 November, 2001

\begin{abstract}
Synthetic manipulations were carried out with the aim of obtaining an advanced linear fragment for production of thermotropic liquid crystals. The chiral fragment synthesised was introduced in a tolanbenzoate mesogenic core by coupling of Sonogashira. The final chiral tolans showed smectic $\mathrm{A}$ and $\mathrm{C}$ and nematic liquid crystalline phases. The crystallographic structure of lactone from (-) menthone is presented.
\end{abstract}

\section{Introduction}

The design and synthesis of new chiral liquid crystals has experienced a great growth, especially of ferroelectric liquid crystals (FLCs). This is due to practical applications of FLCs as high resolution displays and in photonical technologies for storage and reproduction of information based on non-linear optical (NLO) effects [1]. The correlation between molecular chirality and physical properties has been well studied and some models proposed [2]. Conventionally, natural abundant materials like amino acids or commercially available alcohols and esters such as (S)-2-methylbutan-1-ol, (S)-2-methyloctan-1-ol and (S)-ethyl lactate are used to synthesize chiral liquid crystals [3]. (-)-Menthone derivatives have been used only as chiral dopants, to induce ferroelectricity in smectic $\mathrm{C}\left(S_{C}\right)$ liquid crystals or more recently, in photochromic polymers [4]. In all cases the original cyclic structure of (-)-menthone was maintained. In the present work we describe a efficient synthetic approach to transform the (-)-menthone to an appropriate chiral structure which can provide high stereo- and regio-control for liquid crystals synthesis. To verify the efficiency of the chiral chain, we present the synthesis of new liquid crystalline tolanes (diphenylacetylenes) as a continuation of our most recent study $[5]$.

\section{Experimental}

\section{II.1 Tecniques}

${ }^{1} \mathrm{H}-\mathrm{NMR}$ and ${ }^{13} \mathrm{C}-\mathrm{NMR}$ spectra were obtained in
$\mathrm{CDCl}_{3}$ with $270 \mathrm{MHz}$ (Bruker $\mathrm{HX}-270$ ) spectrometer using TMS as internal standard. IR Spectra were recorded in $\mathrm{KBr}$ discs, nujol dispersions or films with a Perkin-Elmer model 283 spectrometer. Elemental analysis was done using a Perkin Elmer 2400CHN. Optical rotations were measured on a Perkin-Elmer 341 polarimeter at the sodium D line. GC analysis was conducted in a Varian 2 equipped with a FID detector using $\mathrm{H}_{2}$ as carrier gas; capillary column used $\beta$-DEX $120(30 \mathrm{~m} \times 0.25 \mathrm{~mm})$. X-ray data were collected in a difratometer Nonius CAD-4; refinement: full-matrix least-squares on $\mathrm{F}^{2}$, GooF $\left(\mathrm{F}^{2}\right)$, programs: solution $\rightarrow$ SHELXS97; refinement $\rightarrow$ SHELXL97; molecular drawing $\rightarrow$ ZORTEP. The thermal transitions and the mesomorphic textures were determined using a Olympus BX 50 polarising microscope in conjunction with a Mettler Toledo FP-90 heating stage and Perkin Elmer DSC-2, using indium as a standard calibration.

The synthetic methodology used was very convenient, it is depicted in scheme 1 .

Baeyer-Villiger oxidation afforded the correspondent lactone (1) [6]. Three oxidation systems were tested on a preparative scale (ca. $10 \mathrm{~g}$ of ketone) and the results obtained are summarized in Table 1 . This is the most important step in the synthesis because the stereo- and regio-control must be guaranteed. NMR experiments $\left({ }^{1} \mathrm{H}, \mathrm{DEPT}, \mathrm{COSY}{ }^{1} \mathrm{H}^{1}{ }^{1} \mathrm{H}\right.$ and HETCOR), chiral capillary GC and X-ray crystal analysis were used for controlling the structure of Baeyer-Villiger oxidation product 1 (Fig. 1 and Table 2). 
<smiles>CC1CCC(C(C)C)C(=O)C1</smiles><smiles>COC(=O)CC(C)CCC(O)C(C)C</smiles><smiles>CCCCOC(CC[C@H](C)CC(=O)O)C(C)C</smiles>

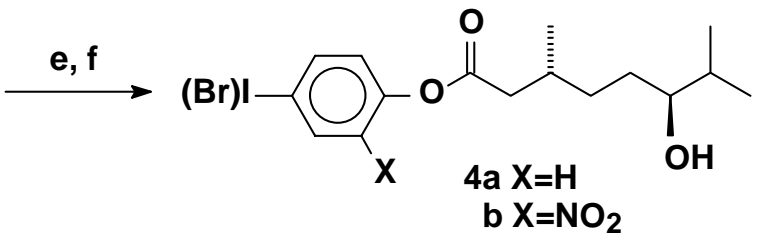

Scheme 1: Regents and conditions a. Baeyer-Villiger oxidation (see table 1). b. $\mathrm{MeOH}, \mathrm{H}_{2} \mathrm{SO}_{4}$ conc., rt, overnight, $(83 \%)$. c. TBDMSCl, imidazol, DMF, rt, 24h (88\%). d. $\mathrm{MeOH}, 2.9 \mathrm{M} \mathrm{KOH}$, reflux, 3h (73\%); e. 4-iodophenol or 2nitro-4-bromophenol, DCC, DMAP, $\mathrm{CH}_{2} \mathrm{Cl}_{2}$, rt, overnight (73\% and $66 \%$ respec.). f. $\mathrm{HF} 48 \% / \mathrm{CH}_{3} \mathrm{CN}$, rt, $15 \mathrm{~min}$, $(>95 \%)$.

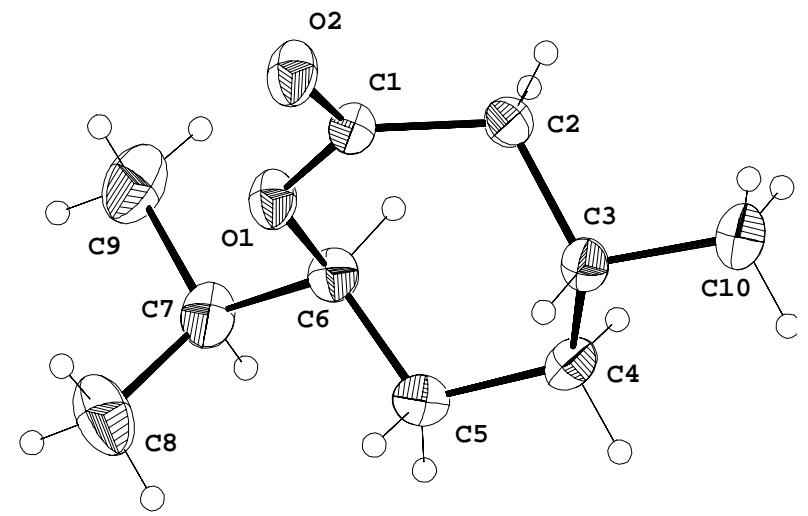

Figure 1. Molecular structure of the lactone from $(3 R, 6 S)$ (-)-6-hydroxy-3,7-dimethyloctanoic acid (1) with atomlabelling scheme. Thermal ellipsoids are shown at $40 \%$ probability level.
Table 1. Baeyer-Villiger oxidation of (-)-menthone.

\begin{tabular}{ccccccc}
\hline Entry & Peracid & $\begin{array}{c}\text { Time } \\
(\mathrm{h})\end{array}$ & $\begin{array}{c}\mathrm{T} \\
\left({ }^{\circ} \mathrm{C}\right)\end{array}$ & Conversion $^{\mathrm{a}}$ & $\begin{array}{c}\text { Yield } \\
(\%)\end{array}$ & $\begin{array}{c}\text { Ketone } \\
\text { recov. } \\
(\%)\end{array}$ \\
\hline 1 & $\mathrm{~b}$ & 66.5 & 25 & Incomplete & 32 & 41 \\
2 & $\mathrm{c}$ & 96.0 & 25 & Incomplete & 70 & 13 \\
3 & $\mathrm{~d}$ & 7.5 & 25 & Complete & 90 & - \\
\hline
\end{tabular}

${ }^{a}$ Monitored by TLC using hexanes/ethyl acetate (7:3) as eluent.

${ }^{\mathrm{b}}$ MCPBA (3-Chloroperoxybenzoic acid).

${ }^{\mathrm{c}} \mathrm{MMPP}$ (Magnesium monoperoxyphtalate hexahydrate).

${ }^{\mathrm{d}} \mathrm{MCPBA} / \mathrm{CF}_{3} \mathrm{CO}_{2} \mathrm{H}$

The chiral precursors (4a and $\mathbf{4 b}$ ) were coupled with a tolanebenzoate mesogenic core to investigate its efficiency in the production of liquid crystals. Scheme 2 illustrates the synthesis of the mesogenic core and the target molecules.

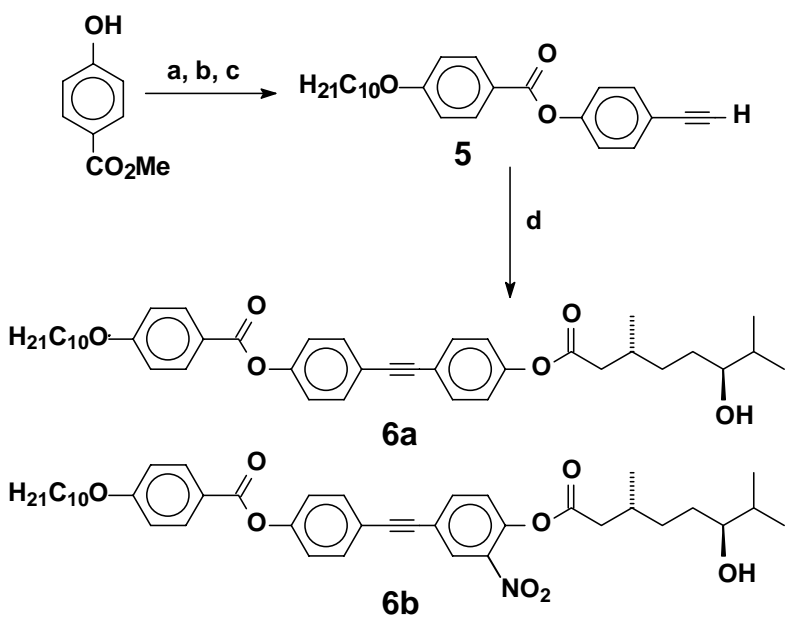

Scheme 2: a. n-decylbromide, $\mathrm{K}_{2} \mathrm{CO}_{3}$, butanone; b. i. $\mathrm{MeOH}, \mathrm{KOH}$; ii. conc. $\mathrm{HCl}(74 \%$ two steps); c. 4ethynylphenol, DCC, DMAP, $\mathrm{CH}_{2} \mathrm{Cl}_{2}(82 \%)$; d. $\mathbf{4 a}$ or $\mathbf{4 b}$, $\mathrm{PdCl}_{2}\left(\mathrm{PPh}_{3}\right)_{2}, \mathrm{CuI}, \mathrm{PPh}_{3}, \mathrm{Et}_{3} \mathrm{~N} / \mathrm{THF}$ (3:1), (51-55\%).

Methyl 4-hydroxybenzoate was alkylated with $\mathrm{n}$ decylbromide by a traditional method. After hydrolysis the resultant acid was esterificated with 4ethynylphenol [7] furnishing the alkyne 5. Palladium catalysed cross-coupling between $\mathbf{5}$ and $\mathbf{4 a}$ or $\mathbf{4 b}$ led to the desired compounds $\mathbf{6 a}$ and $\mathbf{6} \mathbf{b}$. Selected data for final compounds are displayed in the Table 3 . 
Table 2. Crystal data for the lactone from $(3 R, 6 S)-(-)-6$-hydroxy-3,7-dimethyloctanoic acid (1).

\begin{tabular}{ll} 
Empirical formula & $\mathrm{C}_{10} \mathrm{H}_{18} \mathrm{O}_{2}$ \\
Formula weight & 170.24 \\
Temperature $(\mathrm{K})$ & $293(2)$ \\
Wavelength $(\AA)$ & 0.71073 \\
Crystal system, space group & Orthorhombic, $\mathrm{P} 2{ }_{1} 2_{1} 2_{1}$ \\
$\mathrm{a}(\AA)$ & $9.632(2)$ \\
$\mathrm{b}(\AA)$ & $10.273(2)$ \\
$\mathrm{c}(\AA)$ & $10.527(2)$ \\
Volume $\left(\AA^{3}\right)$ & $1041.6(4)$ \\
$Z$, Calculated density $\left({\left.\mathrm{g} . \mathrm{cm}^{-1}\right)}^{-1}\right)$ & $4,1.086$ \\
Absorption coefficient $\left(\mathrm{mm}^{-1}\right)$ & 0.073 \\
$\mathrm{~F}(000)$ & 376 \\
Crystal size $(\mathrm{mm})$ & $0.50 \times 0.40 \times 0.40$ \\
Reflections collected / unique & $1074 / 1074$ \\
Data / restraints / parameters & $1074 / 0 / 110$ \\
GOOF $\left(\mathrm{F}^{2}\right)$ & 1.098 \\
Final indices & $\mathrm{R} 1=0.0409,{ }_{w} \mathrm{R} 2=0.1006$ \\
\hline
\end{tabular}

Table 3: Selected physical and spectroscopic data used to characterize the final compounds.

\begin{tabular}{|c|c|c|c|c|c|}
\hline \multirow{2}{*}{$\begin{array}{l}\text { Com- } \\
\text { pound }\end{array}$} & \multirow[t]{2}{*}{ Optical rotation } & \multicolumn{2}{|c|}{ Elemental analysis } & \multirow[t]{2}{*}{${ }^{1} \mathrm{H}-\mathrm{NMR}(\delta, \mathrm{ppm})$} & \multirow[t]{2}{*}{${ }^{13} \mathrm{C}-\mathrm{NMR}(\delta, \mathrm{ppm})$} \\
\hline & & Calcd for & Found & & \\
\hline $6 a$ & $\begin{array}{l}{[\alpha]_{\mathrm{D}}^{20}-2.0} \\
\left(c 0.65, \mathrm{CHCl}_{3}\right)\end{array}$ & $\begin{array}{l}\mathrm{C}_{41} \mathrm{H}_{52} \mathrm{O}_{6} \\
\mathrm{C} 76.87 \\
\mathrm{H} \quad 8.12\end{array}$ & C 76.23 & $\begin{array}{l}\delta 0.93\left(\mathrm{~m}, 9 \mathrm{H}, 3 \mathrm{CH}_{3}\right), 1.08(\mathrm{~d}, \\
\left.3 \mathrm{H}, J=6.5 \mathrm{~Hz}, \mathrm{CH}_{3}\right), 1.50(\mathrm{~m}, \\
\left.21 \mathrm{H}, 10 \mathrm{CH}_{2} \text { and } \mathrm{CH}\right), 2.10(\mathrm{~m}, \\
1 \mathrm{H}, \mathrm{CH}), 2.40 \quad(\mathrm{dd}, 1 \mathrm{H}, \\
J_{a b}=15.0 \mathrm{~Hz} \text { and } J_{a x}=7.8 \mathrm{~Hz}, \\
-\mathrm{CH}_{\mathrm{a}} \mathrm{HCOOAr}, \mathrm{A} \text { part of } \mathrm{ABX} \\
\text { syst.), } 2.60\left(\mathrm{dd}, 1 \mathrm{H}, J_{a b}=15.0 \mathrm{~Hz}\right. \\
\text { and } \mathrm{J}_{b x}=6.0 \mathrm{~Hz},-\mathrm{CHH}_{\mathrm{b}} \mathrm{COOAr}, \\
\mathrm{B} \text { part of ABX syst. }), 3.35(\mathrm{~m}, \\
1 \mathrm{H},-\mathrm{CH}\left(\mathrm{CH}_{3}\right)_{2} \mathrm{OH}, 4.05(\mathrm{t}, 2 \mathrm{H}, \\
\left.J=6.4 \mathrm{~Hz},-\mathrm{CH}_{2} \mathrm{OAr}\right), 6.97 \quad(\mathrm{~d}, \\
2 \mathrm{H}, J=8.7 \mathrm{~Hz}, \mathrm{Ar}), 7.09(\mathrm{~d}, 2 \mathrm{H}, \\
J=8.5 \mathrm{~Hz}, \mathrm{Ar}), 7.21(\mathrm{~d}, 2 \mathrm{H}, \\
J=8.5 \mathrm{~Hz}, \mathrm{Ar}), 7.56(\mathrm{~m}, 4 \mathrm{H}, \mathrm{Ar}), \\
8.14(\mathrm{~d}, 2 \mathrm{H}, J=8.7 \mathrm{~Hz}, \mathrm{Ar})\end{array}$ & 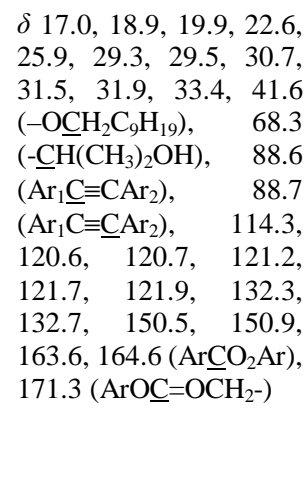 \\
\hline $6 b$ & $\begin{array}{l}{[\alpha]_{\mathrm{D}}^{20}-1.0} \\
\left(c 0.69, \mathrm{CHCl}_{3}\right)\end{array}$ & $\begin{array}{l}\mathrm{C}_{41} \mathrm{H}_{51} \mathrm{NO}_{8} \\
\mathrm{C} 71.82 \\
\mathrm{H} \quad 7.44 \\
\mathrm{~N} \quad 2.04\end{array}$ & $\begin{array}{ll}\mathrm{C} & 71.21 \\
\mathrm{H} & 7.45 \\
\mathrm{~N} & 1.95\end{array}$ & $\begin{array}{l}\delta 0.92\left(\mathrm{~m}, 9 \mathrm{H}, 3 \mathrm{CH}_{3}\right), 1.08(\mathrm{~d}, \\
\left.3 \mathrm{H}, J=6.6 \mathrm{~Hz}, \mathrm{CH}_{3}\right), 1.48(\mathrm{~m}, \\
\left.21 \mathrm{H}, 10 \mathrm{CH}_{2} \text { and } \mathrm{CH}\right), 2.15(\mathrm{~m}, \\
1 \mathrm{H}, \mathrm{CH}), 2.45 \quad(\mathrm{dd}, 1 \mathrm{H}, \\
J_{a b}=15.0 \mathrm{~Hz} \text { and } J_{a x}=7.8 \mathrm{~Hz}, \\
-\mathrm{CH}_{\mathrm{a}} \mathrm{HCOOAr}, \mathrm{A} \text { part of ABX } \\
\text { syst.), } 2.7\left(\mathrm{dd}, 1 \mathrm{H}, J_{a b}=15.0 \mathrm{~Hz}\right. \\
\text { and } J_{b x}=6.0 \mathrm{~Hz},-\mathrm{CHH}_{\mathrm{b}} \mathrm{COOAr}, \\
\mathrm{B} \text { part of ABX syst.), } 4.05(\mathrm{t}, \\
\left.2 \mathrm{H}, J=6.5 \mathrm{~Hz},-\mathrm{CH}_{2} \mathrm{OAr}\right), 6.97 \\
(\mathrm{~d}, 2 \mathrm{H}, \mathrm{J}=8.8 \mathrm{~Hz}, \mathrm{Ar}), 7.21(\mathrm{~d}, \\
2 \mathrm{H}, J=8.7 \mathrm{~Hz}, \mathrm{Ar}), 7.24(\mathrm{~d}, 2 \mathrm{H}, \\
J=8.5 \mathrm{~Hz}, \mathrm{Ar}), 7.60(\mathrm{~d}, 2 \mathrm{H}, \\
J=8.5 \mathrm{~Hz}, \mathrm{Ar}), 7.75(\mathrm{dd}, 1 \mathrm{H}, \\
J=8.7 \text { and } 1.9 \mathrm{~Hz}, \mathrm{Ar}), 8.13(\mathrm{~d}, \\
2 \mathrm{H}, J=8.8 \mathrm{~Hz}, \mathrm{Ar}), 8.22(\mathrm{~d}, 1 \mathrm{H}, \\
J=1.9 \mathrm{~Hz}, \mathrm{Ar})\end{array}$ & 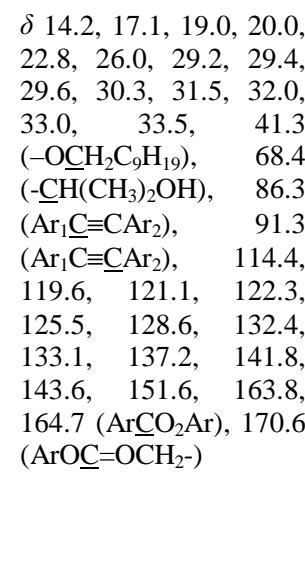 \\
\hline
\end{tabular}




\section{Results and Discussion}

Conventional chiral terminal groups are almost always linear and possess contiguous stereogenic centers. The unique branching points are only the chiral centers. From this point of view the compound $\mathbf{3}$ is not a "conventional" chiral tail such as 2-methyloctanol or aminoacids are. In the compound $\mathbf{3}$ the asymmetric centers are spaced by two atoms of carbon and additionally is present a methyl group at the end of the hydrocarbon chain. However, important factors such as a straight chain and the presence of good linking carboxylate group remain. Methyl branched systems generally show lower clearing points than their linear analogs [8]; presumably because the methyl group sticks out at an angle from the molecular rotational cylinder, and thereby disrupts efficient packing by increasing the separation between neighboring molecules. However, as the methyl branch is moved further away from the core of the mesogen, the clearing point depression is reduced. This demonstrates the greater degree of conformational freedom further away from the core since the effect of branching is less marked [9]. Thus we believe that the methyl group, placed at the last carbon of the main chain in $\mathbf{3}$, does not significantly take effect on the mesomorphic behavior. Also the hydroxyl group may behave in the same way or even help molecular packing by establishing intermolecular hydrogen bonds.

The mesomorphic behavior of the final tolanes was investigated by optical microscopy and the thermal properties are compiled in Table 4 . These compounds exhibited chiral nematic $\left(N^{*}\right)$, smectic A $\left(S_{A}\right)$ and ferroelectric $\left(S_{C} *\right)$ liquid crystalline phases.

Table 4: Selected physical and spectroscopic data used to characterize the final compounds.

\begin{tabular}{cccccc}
\hline Compound & $\mathrm{K}$ & $S_{A}$ & $S_{C}{ }^{*}$ & $N^{*}$ & $\mathrm{I}$ \\
\hline $6 \mathrm{a}$ & $\bullet$ & 113.2 & $\bullet(108.5)$ & $\bullet 164.4$ & $\bullet$ \\
$6 \mathrm{~b}$ & $\bullet$ & 78.6 & $\bullet 105.1$ & $\bullet 128.1$ & $\bullet$ \\
\hline
\end{tabular}

The triple bond between two aromatic rings is interesting, because it contributes to the polarizability, linearity and rigidity of the final molecules. These factors are important and determine many physical properties, such as thermal stability and viscosity in liquid crystals. The presence of the nitro group decreased the melting point expressively (compare $113.2{ }^{\circ} \mathrm{C}$ for compound $6 \mathbf{6 a}$ and $78.6^{\circ} \mathrm{C}$ for compund $\mathbf{6 b}$ ) and also reduced the thermal stability (compare $164.4{ }^{\circ} \mathrm{C}$ for compound $6 \mathbf{a}$ and $128.1^{\circ} \mathrm{C}$ for compound $\mathbf{6 b}$ ). Such behaviour is due the greater van der Waals volume of the nitro group and its effect on molecular packing.

\section{Conclusions}

(-)-Mentone has been transformed into a nearly linear moiety through several chemical reactions including the Baeyer-Villiger oxidation. Two new chiral tolanes were synthesised, one non-laterally substituted $\mathbf{6 a}$ and the other nitro-laterally substituted $\mathbf{6 b}$, using the chiral compound from (-)-mentone. Both compounds showed a $N^{*}$ mesophase and $\mathbf{6 b}$ shows also an enantiotropic $S_{A}$ phase. But undoubtedly, the more exciting result is the $S_{C}$ * ferroelectric mesophase observed for compound $\mathbf{6 a}$, because it proves that compound $\mathbf{3}$ is efficient for producing a $S_{C} *$ phase.

\section{Acknowledgements}

This work was supported by the programs PADCTIII and PRONEX and the agencies CNPq and FAPERGS. We thank Ms Valéria Belli Riatto for the donating reagents and Prof. Ted Ray Taylor for the helpfull discussions.

\section{References}

[1] Macromolecular Host-Guest Complexes: Optical and Optoelectronic Properties and Applications, D. M. Walba, J. A. Rego, N. A. Clark, and R. Shao, Materials Research Soc. 1992; (b) M. Schadt, Liq. Cryst. 14(1), 73, (1993).

[2] (a) T. Sierra, J. L. Serrano, M. B. Ros, A. Ezcurra, and J. Zubia, J. Am. Chem. Soc. 114, 7645, 1992 and references cited therein; (b) J. W. Goobby, I. Nishiyama, A. J. Slaney, C. J. Booth, and K. J. Toyne. Liq. Cryst. 14(1), 37, (1993); (c) C. J. Booth, D. A. Dunmur, J. W. Goodby, and K. J. Toyne. Liq. Cryst. 20(6), 815, (1996).

[3] (a) J. Schacht, P. Zugenmaier, and F. Horh. Liq. Cryst. 26(4), 525, (1999); (b) H. Gallardo, and A. A. Merlo. Synth.Comm., 23(15), 2159, (1993); (c) H. T. Nguyen, J. C. Rouillon, A. Babeau, J. P. Macerou, M. Cotrait, and H. Allouchi. Liq. Cryst. 26(7), 1007, (1999).

[4] (a) A. R. Imamaliev, M. G. Nadzhafova, and D. F. Aliev, Russ. J. Phys. Chem. 67(10), 2023, (1993); (b) L. A. Kutulya, L. D. Patsenker, V. V. Vashchenko, V. P. Kuznetsov, V. I. Kulishov, Y. N. Surov, and V.V. Kravets, Russ. Chem. Bull. 44(7), 1200, (1995); (c) A. Y. Bobrovsky, N.I. Boiko, and V.P. Shibaev, Liq. Cryst. 26(12), 1749, (1999).

[5] A. A. Merlo, J. E. Braun, U. B. Vasconcelos, F. Ely, and H. Gallardo, Liq. Cryst. 27(5), 657, (2000).

[6] S.S.C. Koch and Chamberlin, R. Synth. Comm. 5, 829, (1989).

[7] This compound decomposes with light or heating and was synthesised as described by E. T. Sabourin and A. Onopchenko, J. Org. Chem. 48, 5135, (1983).

[8] G.W. Gray and S.M. Kelly. Mol. Cryst. Liq. Cryst. 104, 335, (1984).

[9] Handbook of Liquid Crystals Research, Collings, P.J. and Patel, J.S., (Oxford University Press, 1997). 